In "Genetic and Evolution of Infectious Diseases" Second Edition. Michel Tibayrenc Editor. Elselvier Publisher. ISBN: 978-0-12-799942-5. 2017

Accepted version after peer-review

\title{
(25) The evolution and dynamics of methicillin-resistant Staphylococcus aureus
}

Mohamed M. H. Abdelbary ${ }^{1}$, Patrick Basset ${ }^{1}$, Dominique S. Blanc ${ }^{1}$, Edward J. Feil ${ }^{2}$

${ }^{1}$ Hospital Preventive Medicine, Centre Hospitalier Universitaire Vaudois and University hospital of Lausanne, Lausanne, Switzerland.

${ }^{2}$ The Milner Centre for Evolution, Department of Biology and Biochemistry, University of Bath, Claverton Down, Bath BA2 7AY, UK.

Keywords: Staphylococcus aureus, antibiotic resistance, SCCmec, epidemiology, mobile genetic elements.

\section{Table of Contents}

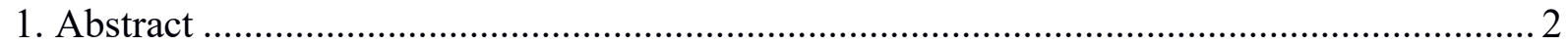

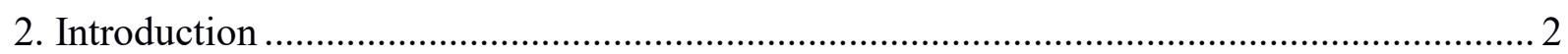

3. The Staphylococcal Cassette Chromosome mec ................................................................ 3

4. Evolution of Staphylococcus aureus and MRSA .............................................................. 5

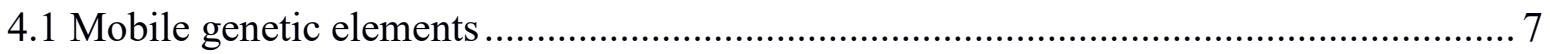

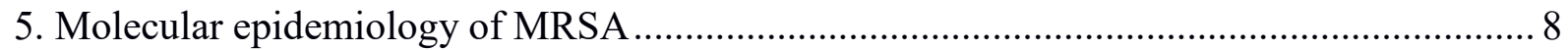

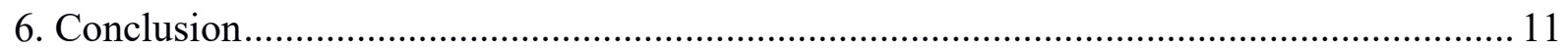

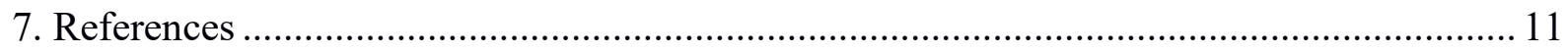




\section{Abstract}

Methicillin-resistant Staphylococcus aureus (MRSA) have been first isolated in 1961, soon after the introduction of methicillin for therapeutic treatments. Since then, the rate of MRSA isolates among $S$. aureus has continuously increased to reach $60 \%$ in some health care institutions. The resistance to methicillin is conferred by the acquisition of the mec $A$ gene, which is located on a large mobile genetic element called the Staphylococcal chromosome cassette mec ( $\mathrm{SCCmec}$ ) and so far eleven types of SCCmec elements have been described (types I to XI). The population structure of $S$. aureus has been shown to be highly clonal and previous genomic comparisons showed that about $75 \%$ of the $S$. aureus genome is highly conserved (core genome), while the remaining $25 \%$ varies significantly among strains (accessory genome). The accessory genome consists mostly of mobile genetic elements, such as bacteriophages, pathogenicity islands, genomic islands, plasmids, transposons, and the SCCmec element. The importance of understanding the patterns of evolution of MGEs is illustrated by the SCCmec element, which has been acquired and/or transferred on multiple occasions during the evolution of the species.

The study of the population genetics of $S$. aureus has been addressed using multilocus sequence typing (MLST). Based on these data, the population structure of $S$. aureus was classified into related groups of strains defined as clonal complexes and their isolated sequence types. Extensive typing showed that the $S$. aureus population associated with humans consists of ten major lineages and most MRSA belong to six of them. The presence of the same clones in different geographical regions suggested their rapid dissemination. Moreover, the epidemiology of MRSA is highly dynamic, and clonal replacement of predominant clones within a given locale has been widely documented. Although the reasons why some clones replace others are unclear, the emergence and replacement of clones might have significant consequences for public health, as different clones possess differing resistance and virulence attributes.

\section{Introduction}

Staphylococcus aureus is a Gram-positive bacterium that typically resides asymptomatically in the anterior nares and the skin of mammals. Since its discovery in the 1880's, it has been recognized as a major opportunistic pathogen in humans, responsible for various diseases, ranging from minor skin infections to severe bacteraemia and necrotising pneumonia. Before the era of antibiotics, the mortality rate of patients infected with $S$. aureus exceeded $80 \%{ }^{1}$. The introduction of penicillin in the early 1940s saved the lives of tens of thousands of wounded allied troops in the Second World War and dramatically improved the prognosis of patients with staphylococcal infections. However, as early as 1942, penicillin-resistant staphylococci were recognized, and these strains arose via the acquisition of a plasmid carrying a gene encoding a penicillinase ( $\beta$-lactamase). Although the spread of penicillin-resistant $S$. aureus was initially confined to hospital settings, this was quickly followed by the wider dissemination of resistance in the community. By the late $1960 \mathrm{~s}$, more than $80 \%$ of both community- and hospital-associated $S$. aureus isolates were resistant to penicillin ${ }^{2}$. This pattern is being repeated for methicillin, an alternative semisynthetic $\beta$-lactam antibiotic that was designed to resist $\beta$ lactamase. Since the introduction of this antibiotic in the 1960s, various hospital-associated methicillin-resistant $S$. aureus (HA-MRSA) clones disseminated worldwide, and virulent 
community-associated MRSA (CA-MRSA) and life stock associated (LA-MRSA) have continued to emerge and spread from the mid-1990s onwards.

\section{The Staphylococcal Cassette Chromosome mec}

Staphylococcus aureus is naturally susceptible to most antibiotics, and resistance is often acquired by the horizontal transfer of genes from intrinsically resistant coagulase-negative staphylococci. These genes are generally located on mobile genetic elements (MGEs) such as plasmids or cassettes.

The resistance to methicillin and all other $\beta$-lactam antibiotics is conferred by the acquisition of the methicillin resistance gene $m e c A^{3}$. This gene is carried on a MGE called the staphylococcal chromosome cassette mec (SCCmec) ${ }^{4}$. This MGE is likely to have been introduced into the $S$. aureus population on multiple occasions from related staphylococcal species ${ }^{5,6}$. Several structural variants of SCCmec have been described, which differ in their gene content and size (21-67 kb), but share four characteristics. First, they carry the mec gene complex (mec) that made up of the methicillin resistance determinants mecA, its expression regulatory genes (mecRl [promoter] and $m e c I$ [repressor]), and the insertion sequence(s). Second, they carry the cassette chromosome recombinase gene complex (ccr), which consists of genes that are responsible for the mobility of the element. Third, they have characteristic repeated sequences at both ends. Fourth, they integrate into the $S$. aureus chromosome at a sitespecific location $(a t t B s c c)$, located within orf $X$ near the origin of replication ${ }^{7-10}$. Despite these common characteristics, the detailed structure of SCCmec elements is highly divergent. In particular, several allotypic differences have been identified in $\mathrm{ccr}$ and $m e c$ complexes ${ }^{11}$, as described below.

ccr gene complex. So far, three distinct $c c r$ genes have been described ( $c c r A, c c r B$, and $c c r C$ ) in $S$. aureus. Whereas $c c r C$ is usually found alone, $c c r A$ and $c c r B$ are generally found adjacently on the same element. In addition, several allotypes of $c c r A$ and $\operatorname{cr} B$ have been identified. The presence of these genes and allotypes has been used to distinguish among the eight different ccr types that are currently observed (Table 1).

mec gene complex. The region of the mec gene complex differs among SCCmec elements in its composition of regulatory genes (mecI and mecRl) and/or insertion sequences (IS431 and IS1272). So far, six classes of mec gene complexes have been described (A, B, C1, C2, D and E) in S. aureus (Table 1).

The typing of SCCmec elements has become essential for several reasons. First, in combination with the genotype of the $S$. aureus chromosome, the SCCmec type is an important characteristic for defining MRSA clones in epidemiological studies and to understand the evolution of these clones ${ }^{12}$. Second, the various SCCmec elements also differ in their patterns of antibiotic susceptibility, which have important clinical implications. For instance, SCCmec type I as well as type IV-VIII cause only resistance to $\beta$-lactam antibiotics. In contrast, the largest SCCmec types II and III cause resistance to multiple classes of antibiotics due to the integration of plasmids or transposons carrying multiple resistance genes within these elements. 
Table 1. Major SCCmec elements identified in S. aureus from (Ito et al., 2009).

\begin{tabular}{|c|c|c|c|c|}
\hline \multicolumn{2}{|c|}{ ccr gene complex } & \multicolumn{2}{|l|}{ mec gene complex } & \multirow{2}{*}{$\begin{array}{l}\text { SCCmec } \\
\text { type }\end{array}$} \\
\hline ccr genes & $\begin{array}{l}c c r \\
\text { type }\end{array}$ & mec genes & $\begin{array}{l}\text { mec } \\
\text { class }\end{array}$ & \\
\hline $\operatorname{ccr} A 1$ & nd & & & \\
\hline $\begin{array}{l}\text { ccrB1 } \\
\operatorname{ccr} A 2\end{array}$ & nd 1 & IS 1272- $\Delta m e c R 1-m e c A-I S 431$ & $\mathrm{~B}$ & I \\
\hline $\operatorname{ccr} B 2$ & 2 & mecI-mecRl-mecA-IS431 & $\mathrm{A}$ & II \\
\hline $\operatorname{ccr} A 3$ & nd & & & \\
\hline $\begin{array}{l}\text { ccrB3 } \\
\operatorname{ccr} A 2\end{array}$ & nd 3 & mecI-mecRl-mecA-IS431 & A & III \\
\hline $\operatorname{ccrB2}$ & 2 & IS $1272-\Delta m e c R 1-m e c A$-IS 431 & $\mathrm{~B}$ & IV \\
\hline $\begin{array}{l}\operatorname{ccr} C \\
\operatorname{cr} A 4\end{array}$ & 5 & IS $431-\Delta m e c R 1-m e c A$-IS 431 & $\mathrm{C} 1^{\mathrm{a}}$ & $\mathrm{V}$ \\
\hline $\operatorname{ccrB} 4$ & 4 & IS 1272-_mecR1-mecA-IS431 & $\mathrm{B}$ & VI \\
\hline $\begin{array}{l}\operatorname{ccr} C \\
\operatorname{ccr} A 4\end{array}$ & $\mathrm{nd}^{5}$ & IS $431-\Delta m e c R 1-m e c A$-IS 431 & $\mathrm{C} 2^{\mathrm{a}}$ & VII \\
\hline $\begin{array}{l}\text { ccrB4 } \\
\text { ccrAl }\end{array}$ & nd 4 & mecI-mecRl-mecA-IS431 & $\mathrm{A}$ & VIII \\
\hline $\begin{array}{l}\text { ccrBl } \\
\text { ccrAl }\end{array}$ & nd 1 & IS 431- $\Delta m e c R 1-m e c A-I S 431$ & $\mathrm{C} 2^{\mathrm{a}}$ & IX \\
\hline $\begin{array}{l}\operatorname{ccr} B 6 \\
\operatorname{ccr} A 1 \\
\operatorname{crB} 3\end{array}$ & nd ${ }^{7}$ & $\begin{array}{l}\text { IS } 431-\Delta m e c R 1-m e c A-I S 431 \\
\text { blaZ-mecALGA251-mecR1LGA251- } \\
\text { mecILGA251 }\end{array}$ & $\mathrm{C} 1^{\mathrm{a}}$ & $X$ \\
\hline
\end{tabular}

${ }^{\mathrm{a}}$ mec class $\mathrm{C} 1$ and $\mathrm{C} 2$ differ in the orientation of IS431 upstream of mecA

Several SCCmec typing methods have been developed, among which the most widely used are based on multiplex PCR assays that identify the different $c c r$ types and mec classes ${ }^{12-16}$. These have a limited number of targets, which may restrict their resolution but can be combined according to the level of discrimination required by the study. Two additional sequence-based typing methods based on the $c c r$ gene complex have also been proposed ${ }^{14,17}$, and these are likely to provide further useful data. Although SCCmec typing is essential for the characterization of MRSA clones in epidemiological studies, it is only recently that a rationalized nomenclature for the SCCmec has been proposed ${ }^{7,11}$.

mec $\boldsymbol{A}$ gene homologue (mecC). Recently, a novel mecA gene homologue, called mecC, has been discovered in the genome of $S$. aureus strain LGA251 that was isolated from bovine mastitis ${ }^{18}$. MRSA strains harbouring $m e c C$ have subsequently been reported from several European countries, and are associated with multiple host species including humans 19-23. Similar to the mecA gene, mecC is located within the SCCmec element (SCCmec type XI) and inserted into the 3' region of $\operatorname{orf} X$. In addition, several $S$. aureus virulence factors, such as adhesions, and toxins were detected among mec $C$ MRSA strains ${ }^{24,25}$. The mec $C$ gene has been detected in several staphylococcal and other related bacterial species, although the origin of $m e c C$ in $S$. aureus remains unclear. 
Currently, a broad range of commercial and PCR-based approaches are available for the detection of mecC MRSA strains, and these have significant diagnostic value for both human and veterinary public health ${ }^{26-29}$.

\section{Evolution of Staphylococcus aureus and MRSA}

Most detailed studies on the population genetics of $S$. aureus have been performed using MLST (Box 1). Based on MLST data, the population of S. aureus was classified into related groups of strains defined as clonal complexes (CCs) and isolated sequence types (STs) ${ }^{30}$. These CCs are considered as different genetic lineages within the $S$. aureus population and only few differences are detected within groups although the characteristics of MGEs (e.g. SCCmec) may vary substantially ${ }^{31}$.

Extensive typing showed that the $S$. aureus population associated with humans consists of ten major lineages (i.e. CC1, CC5, CC8, CC12, CC15, CC22, CC25, CC30, CC45 and CC51), as well as several other minor lineages (Figure 1) ${ }^{15,30,32}$. These lineages have not only been identified using MLST but also using other categories of genes ${ }^{33}$ confirming the biological reality of the CCs. These CCs generally have a radial genetic structure with a founder ST surrounded by numerous single locus variants of the founder. This observation highlights that with the exception of MGEs the genetic diversity within each lineage is remarkably low ${ }^{31,34}$. For example, the non-mobile genome of two strains belonging to CC1 (MW2 and MSSA476) differ at only 285 single nucleotide polymorphisms (SNPs) despite one was a PVL positive MRSA isolated in the USA and the other a PVL negative MSSA isolated in the UK ${ }^{35}$. The low variability observed within CCs might be explained by recent expansion and/or strong purifying selection. Although the relative contribution of each of these factors is difficult to disentangle, purifying selection was described for several categories of genes such as the seven housekeeping genes used for MLST typing, core and accessory adhesion genes ${ }^{36}$ as well as many others ${ }^{37-39}$. This suggests that purifying selection is an important factor that acts on the chromosome of $S$. aureus and it probably affects the diversity observed within CCs.

Another important factor is the low rate of homologous recombination within the core genome of $S$. aureus. Although several chromosomal replacement events were described for $S$. aureus 40,41 , this species has been shown to be highly clonal using a variety of genes: MLST ${ }^{32}$, cell surface sas genes ${ }^{33}$, cell surface core and accessory (i.e. not present in all the strains) adhesion genes $^{36}$, accessory exotoxin-like genes ${ }^{42}$. For example, using MLST data, it was shown that genetic differences between a single locus variant and its ancestral strains were created 15 times more frequently by a point mutation than by a recombination event ${ }^{32}$. This low rate of recombination can help to explain why the clonal complexes have remained discrete and coherent in the $S$. aureus population, and why the same basic groups tend to be defined regardless of the genes used for typing (with the notable exception of $a g r{ }^{43}$ ).

The genetic diversity of MRSA is also known to be much smaller than MSSA ${ }^{44}$ (and the most common MRSA isolates belong to only six CCs (i.e. CC1, CC5, CC8, CC22, CC30 and CC45). In contrast to MSSA, the genetic diversity of MRSA differs considerably among countries and dominant MRSA lineages form distinctive geographical clusters, at least in Europe ${ }^{44}$. This largely reflects the recent origin of many MRSA clones, that is, since the first administration of methicillin in 1961. This means that there has been insufficient time for the MRSA clones to fully homogenize geographically. 


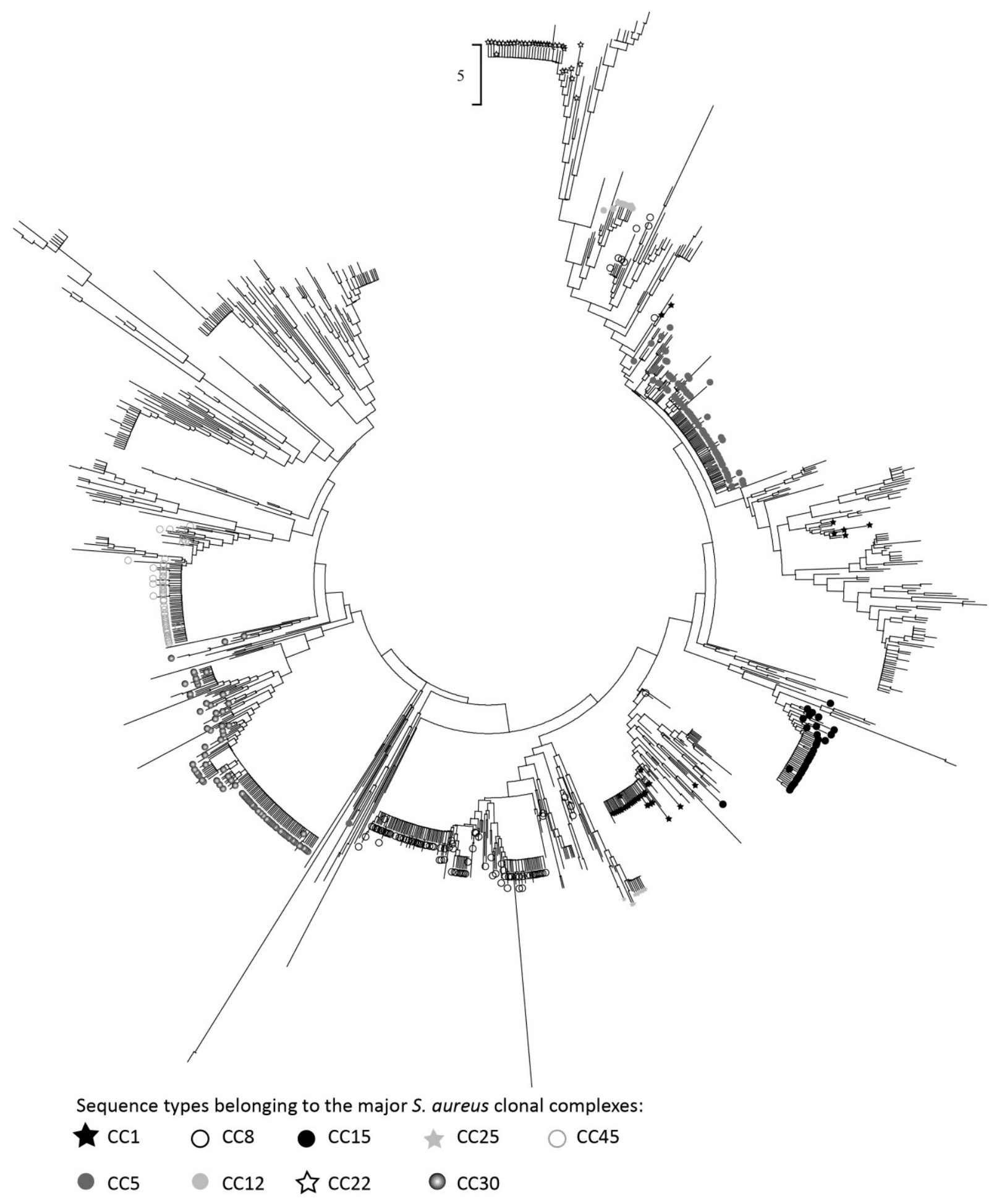

Figure 1 Neighbor-Joining tree of the concatenated sequence of all the STs available in the $S$. aureus MLST database (http://saureus.mlst.net/). The position of the sequence types belonging to major $S$. aureus clonal complexes is indicated by a colored dot. 


\subsection{Mobile genetic elements}

Bacterial genomes can be viewed as two compartments of genes, one comprising "core" genes that are ubiquitously present in all clones of a given species, and the other comprising "accessory" or "non-core" genes that are not present in all isolates in the population, and that have a propensity for horizontal transfer ${ }^{45}$. Whole genome sequence and microarray data have revealed that about $75 \%$ of a typical $S$. aureus genome is present in more than $95 \%$ of the strains (i.e. core genome) ${ }^{46-48}$. As expected, the majority of genes comprising the core genome are composed of species-specific genes and genes associated with central metabolism and other housekeeping function. In contrast, the gene content of the remaining $25 \%$ of the genome varies significantly among strains (i.e. accessory genome).

The accessory genome mostly consists of MGEs, such as bacteriophages, pathogenicity islands, genomic islands, staphylococcal chromosome cassettes (SCCs), plasmids or transposons. Many of these genetic elements carry virulence genes (e.g. tst and PVL which are carried on bacteriophages) ${ }^{48,49}$ and resistance to antibiotics (e.g. mecA carried in SCCmec) ${ }^{30}$. The gene content of a particular $S$. aureus strain is thus a combination of (i) vertical inheritance of its core genome, and (ii) horizontal transfer of MGEs, allowing rapid adaptation by loss or gain of virulence and/or resistance genes ${ }^{48}$. Thus, there is a considerable proportion of the genome that is not essential for survival and that contributes to genetic differences between strains. The distribution and horizontal spread of these elements can have important clinical implications and the characterization of these elements is providing insights into how $S$. aureus is evolving and cause diseases.

Whole genome comparisons indicated important variation in the distribution of genomic islands. This suggests that MGEs are readily exchanged in the $S$. aureus population. For example, genome comparison of one MRSA strain with one MSSA strain showed at least 5 different acquisition/loss events involved in differences in virulence factors and drug resistance 48. Horizontal transfer of MGEs is also suggested by the phylogenetic distribution of these elements, which does not correlate with the genetic relatedness inferred by MLST. This lack of correlation suggests that mobile elements facilitate the exchange of virulence and antibiotic resistance determinants between $S$. aureus lineages and may lead to rapid changes in the pathogenic potential or drug resistance of strains. In contrast, the sequence of the core genome is remarkably constant ${ }^{10,50-53}$.

Several studies suggested that some toxin genes (e.g. toxic shock syndrome toxin 1 (tst), leukocidin DE (lukDE) and superantigens (sea, seg and sei)) are associated with particular lineages (MLST CCs) ${ }^{54,55}$, and there is evidence of frequent acquisition and loss of particular elements that is restricted to particular CCs. Variability of accessory genes such as resistance, toxin or virulence genes, has recently been described within two STs (ST5 and ST228) of CC5 ${ }^{56}$. However, the biological significance and modalities of this intra-strain variability still need to be clarified.

The importance of understanding the patterns of evolution of MGEs is illustrated by the evolution of the SCCmec element. The evolution from MSSA to MRSA involves the acquisition of a SCCmec element by an MSSA strain. The exact mechanisms explaining how the SCCmec elements enter the $S$. aureus cell are not clearly known. However the transduction by phages is often postulated ${ }^{8}$. The frequency of transfer of SCCmec elements as well as their geographical history is also poorly known. Identical clones have been sampled in different countries suggesting a single SCCmec acquisition, followed by clonal spread. Yet, the presence of multiple SCCmec types in MRSA suggests multiple introductions into S. aureus. Moreover, the 
occurrence of isolates with identical ST but with different SCCmec types indicates that horizontal transfer of SCCmec elements is relatively frequent within S. aureus ${ }^{30}$. Using MLST, it has been shown that the SCCmec element must have been acquired on multiple occasions (at least 20 times) during $S$. aureus evolution ${ }^{17,30,33}$. A previous study based on SNPs discovery on a worldwide collection of ST 5 showed a close association between phylogenetic lineages and geography ${ }^{31}$. These data suggest that geographical spread of MRSA over long distance is a rare event compared with the frequency with which the SCCmec is imported locally. Moreover, MSSA strains genetically identical to the predominant MRSA strains have been observed at a local level ${ }^{57,58}$, confirming the possibility of local acquisitions of the SCCmec.

\section{Molecular epidemiology of MRSA}

Epidemiological surveillance of MRSA has been greatly facilitated by the development of molecular typing procedures. The grouping of isolates into clones depends on the typing method used (e.g. PFGE, MLST, spa typing, and recently whole-genome sequencing) (Box 1). MLST provides a robust-typing system by grouping related $S$. aureus strains into distinct sequence types (STs) based on the sequences of internal fragments of seven housekeeping genes ${ }^{30}$. However, as MLST is only based on the variation within a very small proportion of the genome, much of the fine molecular microevolutionary detail such single nucleotide polymorphisms (SNPs), genome re-arrangements and small INDELS remains undetected. Even before the advent of whole genome sequencing, it was clear that single MLST genotypes often encompassed multiple types as defined by other techniques. For example, ST 239 includes EMRSA 1, 4, 11 and the Brazilian, Portuguese, Viennese and Hungarian clones, and ST 5 includes the New York/Japan and the Paediatric clones, as defined by PFGE, spa- and/or SCCmec-typing ${ }^{59}$. Similarly, two Swiss clones (clone D and G) were indistinguishable by MLST, exhibited identical STs (ST228), SCCmec type I and virulence gene content as determined by PCR yet differed by 16 bands by PFGE ${ }^{60}$. These differences were likely the result of the gain or loss of mobile genetic elements (MGEs) such as phage, which would not be detected by other approaches. In contrast, in other cases micro-variation is detected by MLST and other methods (such as individual SNPs) but not by PFGE. None of the traditional typing methods provided optimal resolution in all cases. The advent of whole-genome sequencing has provided such a "once size fits all" approach, in that it provides unprecedented discriminatory power for epidemiological surveillance, outbreak investigations and for better understanding of the evolutionary dynamics of both the core and non-core genome of MRSA. [Please Insert Box 1 about here]

Many studies have demonstrated that high frequencies of MRSA within a given location tend to reflect the clonal spread of only one or two clones (e.g. ${ }^{59-67}$ ). The domain of dominance of specific clones can range in size from a single hospital, single country, or even neighbouring countries ${ }^{68-70}$. Analysis of more than 3,000 isolates from Southern Europe, USA and South America showed that nearly $70 \%$ of them belong to 5 major pandemic clones, namely the Iberian (ST247-SCCmec I), Brazilian (ST239-SCCmec III), Hungarian (ST239-SCCmec III), New York/Japan (ST5-SCCmec II), and Pediatric (ST5-SCCmec IV) clones 15, 59, 71. The addition of three more clones would essentially encompass Northern Europe: the EMRSA-15 (ST22-SCCmec IV), EMRSA-16 (ST36-SCCmec II) and Berlin (ST45-SCCmec IV) clones ${ }^{30}$. Therefore, it was hypothesized that these clones are particularly transmissible and/or well adapted to the hospital environment ${ }^{72,73}$.

The epidemiology of MRSA is highly dynamic, and clonal replacement of predominant clones within a given locale has been widely documented. Whereas cross-sectional studies showed the 
predominance of one or two clones in a defined setting in the 90 's, several longitudinal studies showed the replacement of the predominant clones by others within a decade ${ }^{59,74}$. A very early example was the replacement in England of EMRSA-1 (ST239) by EMRSA-15 and -16 ${ }^{73}$ Other ST239 variants (e.g. in particular the Brazillian clone and the Hungarian clone) have subsequently become very widespread throughout South America, Eastern Europe and mainland Asia (including both China and the middle East), where this genotype may account for at least $90 \%$ of all cases of HA-MRSA. Additionally, another pandemic clone replaced the Iberian clone on at least two occasions. It was first replaced by EMRSA-16 in one Spanish hospital while the rate of MRSA among $S$. aureus remained constant ${ }^{74}$, and by the Brazilian clone in one Portuguese hospital ${ }^{75}$. The fact that on both occasions the Iberian clone was replaced might suggest that it lost its epidemic potential during the last decade. Other examples are the complete replacement in a 2-year period of a local clone (ST5-SCCmec IV) by the New York/Japan clone (ST5-SCCmec II) in a Mexico City hospital (Velazquez-Meza et al., 2004) and the replacement of the Berlin clone by a variant from the New York/Japan clone (ST105SCCmec II) and by the South Germany clone (ST228- SCCmec I) in an area of low MRSA incidence in Western Switzerland ${ }^{60}$. Although the reasons why some clones replace others are typically unclear, the emergence and replacement of clones might have significant public health consequences as different clones possess differing resistance and virulence attributes ${ }^{74-80}$. For instance, during the 1990s in France, the replacement of the Iberian clone (ST 247- SCCmec I) by the Lyon clone (ST8- SCCmec IV) resulted in a change of the susceptibility profile to antibiotics, the Iberian clone being less susceptible than the Lyon clone (e.g. to gentamicin and co-trimoxasole) ${ }^{76}$.

For regions outside of Europe, North America and Australia the picture may be different. For example, ST239 that probably emerged in the mid $1960 \mathrm{~s}^{34}$ is a probable major cause of HAMRSA infection throughout mainland Asia and South America, a geographical region that holds more than $50 \%$ of the world's human population ${ }^{81}$. This sequence type always exhibits a variant of the large SCCmec type III; however, four cases of HA-MSSA ST239 were detected in China ${ }^{82}$. ST239 is rarely found outside of the hospital setting, which makes its rapid global dissemination, which must have occurred largely through very short transmission chains between hospitals, even more remarkable.

Perhaps of greatest concern is the emergence of specific MRSA clones within the community. Up until the 1990s, MRSA was found to be restricted to hospitals, but the 2000s have witness a dramatic increase in virulent MRSA clones in the community (CA-MRSA) ${ }^{83}$. These clones are generally characterized by the presence of a SCCmec type IV or V and the phage-borne genes encoding the Panton-Valentine leukocidin (PVL) toxin. This toxin is widely considered to be an important virulence factor, particularly for paediatric infection. Molecular typing has revealed that CA-MRSA clones are distinct from those noted in hospital settings ${ }^{67,84}{ }^{\text {. ST } 80-}$ SCCmec IV provides a notable example of an emerging CA-MRSA clone, which is currently restricted to several European communities with low social status (e.g. homeless people). Although the widespread HA-MRSA does not appear to have adapted to the community, it seems that clones that emerge in the community may be able to spread in hospitals. For example, ST8-SCCmec IV (generally called the USA300 clone) spread mainly in the USA, initially in the community but is currently also causing a major burden in hospital settings ${ }^{85,86}$. In countries with low incidence of hospital MRSA such as northern European countries, CAMRSA has become a major concern ${ }^{87}$.

The spread of community-acquired MRSA clones is possibly related to the small size of the SCCmec types IV and V. There is a trade-off to the acquisition of resistance, which is that it 
imparts of fitness cost which may render the strain uncompetitive against susceptible strains when antibiotics are not present in the environment. This is thought to be the reason why infection, and carriage, of HA-MRSA clones have remained largely confined to health-care settings. The smaller type IV and V SCCmec cassettes do not confer multiple resistances, but may also result in a smaller fitness cost.

Although the epidemiological distinctions between CA-MRSA and HA-MRSA can be largely explained in terms of the fitness cost of resistance, the more general question of why a single MRSA clone can predominate in a given area, or the forces underlying clonal replacement, are far less well understood. It is probable that genetic differences underlie increased or decreased fitness (transmissibility) ${ }^{61,72,73,88,89}$, and some general traits have been identified, which may account for epidemic spread. These include the ability to survive in the environment, to colonize the host, to multiply on epithelial and mucosal surfaces, to "detach" from the host, and to resist to various antimicrobials. However, stochastic effects and extrinsic factors, such as local compliance to infection control measures and local use of antibiotics, may also have unpredictable consequences for the local composition of circulating MRSA clones. Furthermore, the specific genetic differences corresponding to fitness effects are very difficult to identify due to extensive gene redundancy and the possibility of subtle epistatic or regulatory effects playing a major role. The precise relationship between the "spread" (epidemicity) of a clone, and its virulence potential, is also unclear.

These complications can perhaps explain why a number of studies drawing comparisons between epidemic and sporadic MRSA have not generated clear experimental evidence consistent with the different epidemiological patterns ${ }^{90-96}$. An exception is a study demonstrating differences in biofilm production and adhesion to epithelial cells within epidemic variants of the Brazillian clone (ST239-III) ${ }^{97}$. Although these laboratory comparisons were carried out on a small sample of strains, an epidemiological study also found evidence for increased virulence of an ST239 variant (TW20) which caused a recent outbreak in a London hospital ${ }^{98}$.

Molecular approaches have also not provided a clear understanding of epidemiological differences between clones. Population genetic analyses based on nucleotide sequence data of both housekeeping (MLST) genes and cell surface adhesion genes (which play a key role in host invasion) have also largely failed to detect robust links between genotype and epidemic phenotype ${ }^{36}$. Comparative genome hybridization and WGS have also been used to compare epidemic and sporadic strains but this approach also failed to identify any genes likely to play a major role in increased transmission 99,100 . These findings are strong evidence against the presence or absence of a single common specific factor differentiating epidemic from sporadic S. aureus clones.

Although the evidence linking genotype and epidemiological phenotype is in many cases weak, there are tantalizing clues. For example, the CA-MRSA strain USA300 has disseminated widely throughout the United States. Genome sequencing of this strain revealed a novel genetic element, the arginine catabolic mobile element (ACME), which contained the gene for the arginine deiminase that may play a crucial role in the growth and survival of the bacterial cells 50,101 . However, recent studies have shown that among $9 \%$ to $15 \%$ of the USA300 strains do not carry the ACME genomic region ${ }^{102}$. In addition, genome sequencing of 10 other isolates from the same disseminating clone confirmed its recent expansion ${ }^{103}$. Similarly, for the multidrug-resistant ST59 strains, a clone that is predominant in Taiwan has truncated $h s d M$ and $h s d S$ genes that encode the restriction-modification system. Hence, it was suggested that this 
deficiency in the restriction-modification system might have assisted the acquisition of mobile genetic elements from enterococci, which confer multi-drug resistance ${ }^{104}$.

Besides being a human pathogen, S. aureus also colonizes the skin of animals and can cause a wide range of infections ${ }^{105-107}$. Livestock-associated MRSA (LA-MRSA) strains attract particular attention as the potential for zoonotic transmission raises the concern for public health. Previous reports have shown that distinct MRSA genotypes are associated with specific animal species. However, several studies have documented the transmission of LA-MRSA among different host species (e.g. from animals to humans and vice versa) ${ }^{108-110}$. For instance, the LA-MRSA CC398 was first detected in pig farms and farmers from Europe, and has since been discovered to colonise and cause infections in other animals species (e.g. poultry, horses, dogs and cattle) and humans worldwide ${ }^{111-115}$. Furthermore, CC398 was reported from humans lacking direct contact with livestock or livestock workers ${ }^{116-118}$. A study based on the wholegenome sequencing approach, demonstrated that CC398 originated in human as MSSA and was transmitted to livestock, where it subsequently acquired methicillin resistance ${ }^{119}$. Likewise, phylogenetic analysis of the MRSA CC5 poultry strains revealed that they have originated in humans and later transmitted to poultry, where it subsequently acquired avian-specific MGEs 110. In contrast, it was shown that the human pandemic MRSA CC97 strains recently made a bovine-to-human jump ${ }^{120}$. Taken together, these findings indicate that host-switches have been a feature in the evolution of a number of MRSA clones.

\section{Conclusion}

The widespread occurrence of MRSA in hospitals is recognized as a major challenge, especially with the recent emergence of strains with intermediate susceptibility to glycopeptides and of community-acquired MRSA. Given the difficulties to control MRSA, a thorough understanding of the processes underlying the emergence and spread of MRSA may help designing new strategies to counteract this evolution. Several major pandemic clones have been identified and their epidemiology may change rapidly at a regional scale. Changes in clones have significant medical consequences, since the new clones often display different antibiotic susceptibility and/or virulence patterns.

The advance of recent sequencing technologies and the development of associated bioinformatics tools will provide a superior depth in the understanding of MRSA evolutionary history. These data will allow addressing many important questions about the evolution and epidemiology of MRSA and will bridge the gap left by the low discriminatory power of MLST. However, certain challenges concerning whole-genome sequencing still need to be addressed including choosing the proper strains collection, the development of standardized analysis pipeline, and the large-scale data management.

\section{References}

1. Skinner D and Keefer CS. Significance of bacteremia caused by Staphylococcus aureus - A study of one hundred and twenty-two cases and a review of the literature concerned wiih experimental infection in animals. Archives of Internal Medicine. 1941; 68: 851-75.

2. Lowy FD. Antimicrobial resistance: the example of Staphylococcus aureus. J Clin Invest. 2003; 111: $1265-73$. 
3. Matsuhashi M, Song MD, Ishino F, et al. Molecular cloning of the gene of a penicillin-binding protein supposed to cause high resistance to beta-lactam antibiotics in Staphylococcus aureus. The Journal of Bacteriology. 1986; 167: 975-80.

4. Katayama Y, Ito T and Hiramatsu K. A new class of genetic element, staphylococcus cassette chromosome mec, encodes methicillin resistance in Staphylococcus aureus. Antimicrob Agents Chemother. 2000; 44: 1549-55.

5. Couto I, Wu SW, Tomasz A and de Lencastre H. Development of Methicillin Resistance in Clinical Isolates of Staphylococcus sciuri by Transcriptional Activation of the mecA Homologue Native to the Species. The Journal of Bacteriology. 2003; 185: 645-53.

6. Ibrahem S, Salmenlinna S, Virolainen A, et al. Carriage of Methicillin-Resistant Staphylococci and Their SCCmec Types in a Long-Term-Care Facility. Journal of Clinical Microbiology. 2009; 47: 32-7.

7. Chongtrakool P, Ito T, Ma XX, et al. Staphylococcal Cassette Chromosome mec (SCCmec) Typing of Methicillin-Resistant Staphylococcus aureus Strains Isolated in 11 Asian Countries: a Proposal for a New Nomenclature for SCCmec Elements. Antimicrobial Agents and Chemotherapy. 2006; 50: 100112.

8. de Lencastre $\mathrm{H}$, Oliveira $\mathrm{D}$ and Tomasz A. Antibiotic resistant Staphylococcus aureus: a paradigm of adaptive power. Current Opinion in Microbiology. 2007; 10: 428-35.

9. Hiramatsu K, Cui L, Kuroda M and Ito T. The emergence and evolution of methicillin-resistant Staphylococcus aureus. Trends in Microbiology. 2001; 9: 486-93.

10. Kuroda $\mathrm{M}$, Ohta $\mathrm{T}$, Uchiyama $\mathrm{I}$, et al. Whole genome sequencing of meticillin-resistant Staphylococcus aureus. Lancet. 2001; 357: 1225-40.

11. Ito T, Hiramatsu K, Oliveira DC, et al. Classification of Staphylococcal Cassette Chromosome mec (SCCmec): Guidelines for Reporting Novel SCCmec Elements. Antimicrobial Agents and Chemotherapy. 2009; 53: 4961-7.

12. Okon KO, Basset $P$, Uba A, et al. Cooccurrence of predominant Panton-Valentine leukocidinpositive sequence type (ST) 152 and multidrug-resistant ST 241 Staphylococcus aureus clones in Nigerian hospitals. J Clin Microbiol. 2009; 47: 3000-3.

13. Hanssen AM and Sollid JUE. Multiple staphylococcal cassette chromosomes and allelic variants of cassette chromosome recombinases in Staphylococcus aureus and coaaulase-neizative stahylococci from Norway. Antimicrobial Agents and Chemotherapy. 2007; 51: 1671-7.

14. Miragaia M, Couto I and De Lancastre H. Genetic diversity among methicillin-resistant Staphylococcus epidermidis (MRSE). Microbial Drug Resistance-Mechanisms Epidemiology and Disease. 2005; 11: 83-93.

15. Kondo $\mathrm{Y}, \mathrm{Abe} \mathrm{H}$, Jinmei $\mathrm{H}$, et al. Multiple chemical ligation under thermal cycle. Nucleic Acids Symp Ser (Oxf). 2007: 353-4.

16. Milheirico $C$, Oliveira DC and de Lencastre $H$. Update to the multiplex PCR strategy for assignment of mec element types in Staphylococcus aureus. Antimicrobial Agents and Chemotherapy. 2007; 51: 4537-.

17. Oliveira DC, Milheirico $C$, Vinga $S$ and de Lencastre $H$. Assessment of allelic variation in the ccrAB locus in methicillin-resistant Staphylococcus aureus clones. Journal of Antimicrobial Chemotherapy. 2006; 58: 23-30.

18. Oliveira DC, Tomasz A and de Lencastre H. Secrets of success of a human pathogen: molecular evolution of pandemic clones of meticillin-resistant Staphylococcus aureus. Lancet Infect Dis. 2002; 2: 180-9.

19. Oliveira DC and de Lencastre H. Multiplex PCR strategy for rapid identification of structural types and variants of the mec element in methicillin-resistant Staphylococcus aureus. Antimicrobial Agents and Chemotherapy. 2002; 46: 2155-61.

20. Lina G, Durand G, Berchich C, et al. Staphylococcal chromosome cassette evolution in Staphylococcus aureus inferred from ccr gene complex sequence typing analysis. ClinMicrobiolinfect. 2006; 12: 1175-84. 
21. Garcia-Alvarez L, Holden MT, Lindsay $\mathrm{H}$, et al. Meticillin-resistant Staphylococcus aureus with a novel mecA homologue in human and bovine populations in the UK and Denmark: a descriptive study. Lancet Infect Dis. 2011; 11: 595-603.

22. Monecke S, Gavier-Widen D, Mattsson R, et al. Detection of mecC-positive Staphylococcus aureus (CC130-MRSA-XI) in diseased European hedgehogs (Erinaceus europaeus) in Sweden. PLoS One. 2013; 8: e66166.

23. Paterson GK, Harrison EM and Holmes MA. The emergence of mecC methicillin-resistant Staphylococcus aureus. Trends Microbiol. 2014; 22: 42-7.

24. Basset P, Prod'hom G, Senn L, Greub G and Blanc DS. Very low prevalence of meticillin-resistant Staphylococcus aureus carrying the mecC gene in western Switzerland. J Hosp Infect. 2013; 83: 257-9. 25. Kerschner $\mathrm{H}$, Harrison EM, Hartl R, Holmes MA and Apfalter P. First report of mecC MRSA in human samples from Austria: molecular characteristics and clinical data. New microbes and new infections. 2015; 3: 4-9.

26. Paterson GK, Morgan FJ, Harrison EM, et al. Prevalence and characterization of human mecC methicillin-resistant Staphylococcus aureus isolates in England. J Antimicrob Chemother. 2014; 69: 90710.

27. Cuny C, Layer F, Strommenger B and Witte W. Rare Occurrence of Methicillin-Resistant Staphylococcus aureus CC130 with a Novel mecA Homologue in Humans in Germany. PLoS ONE. 2011; 6: e24360-.

28. Harrison EM, Paterson GK, Holden MT, et al. Whole genome sequencing identifies zoonotic transmission of MRSA isolates with the novel mecA homologue mecC. EMBO molecular medicine. 2013; 5: 509-15.

29. Stegger M, Lindsay JA, Moodley A, Skov R, Broens EM and Guardabassi L. Rapid PCR detection of Staphylococcus aureus clonal complex 398 by targeting the restriction-modification system carrying sau1-hsdS1. J Clin Microbiol. 2011; 49: 732-4.

30. Pichon B, Hill R, Laurent $F$, et al. Development of a real-time quadruplex PCR assay for simultaneous detection of nuc, Panton-Valentine leucocidin (PVL), mecA and homologue mecALGA251. J Antimicrob Chemother. 2012.

31. Becker K, Denis O, Roisin S, et al. Detection of mecA- and mecC-Positive Methicillin-Resistant Staphylococcus aureus (MRSA) Isolates by the New Xpert MRSA Gen 3 PCR Assay. J Clin Microbiol. 2016; 54: 180-4.

32. Becker K, Larsen AR, Skov RL, et al. Evaluation of a modular multiplex-PCR methicillin-resistant Staphylococcus aureus detection assay adapted for mecC detection. J Clin Microbiol. 2013; 51: 19179.

33. Enright MC, Robinson DA, Randle G, Feil EJ, Grundmann H and Spratt BG. The evolutionary history of methicillin-resistant Staphylococcus aureus (MRSA). Proc Natl Acad Sci U S A. 2002; 99: 768792.

34. Nübel $U$, Roumagnac $P$, Feldkamp $M$, et al. Frequent emergence and limited geographic dispersal of methicillin-resistant Staphylococcus aureus. Proc Natl Acad Sci U S A. 2008; 105: 14130-5. 35. Feil EJ, Cooper JE, Grundmann H, et al. How clonal is Staphylococcus aureus? Journal of Bacteriology. 2003; 185: 3307-16.

36. Robinson DA and Enright MC. Evolutionary models of the emergence of methicillin-resistant Staphylococcus aureus. Antimicrobial Agents and Chemotherapy. 2003; 47: 3926-34.

37. Harris SR, Feil EJ, Holden MT, et al. Evolution of MRSA during hospital transmission and intercontinental spread. Science. 2010; 327: 469-74.

38. Lindsay JA. Genomic variation and evolution of Staphylococcus aureus. International Journal of Medical Microbiology. 2010; 300: 98-103.

39. Kuhn G, Francioli P and Blanc DS. Evidence for clonal evolution among highly polymorphic genes in methicillin-resistant Staphylococcus aureus. Journal of Bacteriology. 2006; 188: 169-78. 
40. Cooper JE and Feil EJ. The phylogeny of Staphylococcus aureus - which genes make the best intra-species markers? Microbiology-Sgm. 2006; 152: 1297-305.

41. Hughes AL and Friedman R. Nucleotide substitution and recombination at orthologous loci in Staphylococcus aureus. Journal of Bacteriology. 2005; 187: 2698-704.

42. Sabat A, Wladyka B, Kosowska-Shick K, et al. Polymorphism, genetic exchange and intragenic recombination of the aureolysin gene among Staphylococcus aureus strains. Bmc Microbiology. 2008; 8: 129 -

43. Narra HP and Ochman H. Of What Use Is Sex to Bacteria? Current Biology. 2006; 16: R705-R10. 44. Robinson DA and Enright MC. Evolution of Staphylococcus aureus by large chromosomal replacements. Journal of Bacteriology. 2004; 186: 1060-4.

45. Fitzgerald JR, Reid SD, Ruotsalainen E, et al. Genome diversification in Staphylococcus aureus: Molecular evolution of a highly variable chromosomal region encoding the Staphylococcal exotoxinlike family of proteins. Infect/mmun. 2003; 71: 2827-38.

46. Robinson DA, Monk AB, Cooper JE, Feil EJ and Enright MC. Evolutionary genetics of the accessory gene regulator (agr) locus in Staphylococcus aureus. Journal of Bacteriology. 2005; 187: 8312-21.

47. Grundmann H, Aanensen DM, van den Wijngaard CC, et al. Geographic distribution of Staphylococcus aureus causing invasive infections in Europe: a molecular-epidemiological analysis. PLoS Med. 2010; 7: e1000215.

48. Lan RT and Reeves PR. Intraspecies variation in bacterial genomes: the need for a species genome concept. Trends in Microbiology. 2000; 8: 396-401.

49. El Garch F, Hallin M, De Mendonca R, Denis O, Lefort A and Struelens MJ. StaphVar-DNA microarray analysis of accessory genome elements of community-acquired methicillin-resistant Staphylococcus aureus. Journal of Antimicrobial Chemotherapy. 2009; 63: 877-85.

50. Fitzgerald JR, Sturdevant DE, Mackie SM, Gill SR and Musser JM. Evolutionary genomics of Staphylococcus aureus: insights into the origin of methicillin-resistant strains and the toxic shock syndrome epidemic. ProcNatIAcadSciUSA. 2001; 98: 8821-6.

51. Lindsay JA and Holden MT. Staphylococcus aureus: superbug, super genome? Trends Microbiol. 2004; 12: 378-85.

52. Loffler B, Hussain M, Grundmeier M, et al. Staphylococcus aureus panton-valentine leukocidin is a very potent cytotoxic factor for human neutrophils. PLoS Pathog. 2010; 6: e1000715.

53. Highlander SK, Hulten KG, Qin X, Jiang H, Yerrapragada $\mathrm{S}$ and al. e. Subtle genetic changes enhance virulence of methicillin resistant and sensitive Staphylococcus aureus. BMC Microbiol. 2007; 7: 99-.

54. Holden MT, Feil EJ, Lindsay JA, Peacock SJ, Day NP and al. e. Complete genomes of two clinical Staphylococcus aureus strains: evidence for the rapid evolution of virulence and drug resistance. ProcNatIAcadSciUSA. 2004; 101: 9786-91.

55. Ohta T, Hirakawa H, Morikawa K, et al. Nucleotide substitutions in Staphylococcus aureus strains, Mu50, Mu3, and N315. DNA Res. 2004; 11: 51-6.

56. Sivaraman K, Venkataraman N, Tsai J, Dewell S and Cole AM. Genome sequencing and analysis reveals possible determinants of Staphylococcus aureus nasal carriage. BMC Genomics. 2008; 9: 433-.

57. Moore PC and Lindsay JA. Genetic variation among hospital isolates of methicillin-sensitive Staphylococcus aureus: evidence for horizontal transfer of virulence genes. Journal of Clinical Microbiology. 2001; 39: 2760-7.

58. Peacock SJ, Moore CE, Justice A, et al. Virulent combinations of adhesin and toxin genes in natural populations of Staphylococcus aureus. Infection and Immunity. 2002; 70: 4987-96.

59. Monecke S, Ehricht R, Slickers $P$, Wiese $N$ and Jonas $D$. Intra-strain variability of methicillinresistant Staphylococcus aureus strains ST228-MRSA-I and ST5-MRSA-II. European Journal of Clinical Microbiology \& Infectious Diseases. 2009; 28: 1383-90. 
60. Enright MC, Day NP, Davies CE, Peacock SJ and Spratt BG. Multilocus sequence typing for characterization of methicillin-resistant and methicillin-susceptible clones of Staphylococcus aureus. Journal of Clinical Microbiology. 2000; 38: 1008-15.

61. Hallin M, Denis O, Deplano A, et al. Genetic relatedness between methicillin-susceptible and methicillin-resistant Staphylococcus aureus: results of a national survey. Journal of Antimicrobial Chemotherapy. 2007; 59: 465-72.

62. Aires de Sousa $\mathrm{M}$ and de Lencastre $\mathrm{H}$. Bridges from hospitals to the laboratory: genetic portraits of methicillin-resistant Staphylococcus aureus clones. FEMS ImmunolMedMicrobiol. 2004; 40: 101-11.

63. Blanc DS, Petignat C, Wenger A, et al. Changing molecular epidemiology of methicillin-resistant Staphylococcus aureus in a small geographic area over an eight-year period. J Clin Microbiol. 2007; 45: 3729-36.

64. Aparicio P, Richardson J, Martin S, Vindel A, Marples RR and Cookson BD. An epidemic methicillin-resistant strain of Staphylococcus aureus in Spain. Epidemiollnfect. 1992; 108: 287-98.

65. de Lencastre $H$, Severina EP, Milch $H$, Konkoly Thege $M$ and Tomasz A. Wide geographic disctribution of a unique methicillin-resistant Staphylococcus aureus clone in Hungarian hospitals. Clinical Microbiology and Infection. 1997; 3: 289-96.

66. Deplano A, Witte W, van Leeuwen WJ, Brun Y and Struelens MJ. Clonal dissemination of epidemic methicillin-resistant Staphylococcus aureus in Belgium and neighboring countries. ClinMicrobiollnfect. 2000; 6: 239-45.

67. Gomes AR, Sanches IS, ires de SM, Castaneda E and de LH. Molecular epidemiology of methicillin-resistant Staphylococcus aureus in Colombian hospitals: dominance of a single unique multidrug-resistant clone. MicrobDrug Resist. 2001; 7: 23-32.

68. Leski T, Oliveira D, Trzcinski K, et al. Clonal distribution of methicillin-resistant Staphylococcus aureus in Poland. Journal of Clinical Microbiology. 1998; 36: 3532-9.

69. Melter O, Santos S, I, Schindler J, et al. Methicillin-resistant Staphylococcus aureus clonal types in the Czech Republic. Journal of Clinical Microbiology. 1999; 37: 2798-803.

70. Oliveira D, Santos Sanches I, Mato R, et al. Virtuallay all methicillin-resistant Staphylococcus aureus (MRSA) infections in the largest Portuguese teaching hospital are caused by two internationally spread multiresistant strains: the "Iberian" and the "Brazilian" clones of MRSA. Clinical Microbiology and Infection. 1998; 4: 373-84.

71. Aires de Sousa M, Sanches IS, van BA, van LW, Verbrugh $H$ and de Lencastre H. Characterization of methicillin-resistant Staphylococcus aureus isolates from Portuguese hospitals by multiple genotyping methods. Microb Drug Resist. 1996; 2: 331-41.

72. Ayliffe GA. The progressive intercontinental spread of methicillin-resistant Staphylococcus aureus. ClinInfectDis. 1997; 24 Suppl 1: S74-S9.

73. Mato R, Sanches S, Venditti M, et al. Spread of the multiresistant Iberian clone of methicillinresistant Staphylococcus aureus (MRSA) to Italy and Scotland. Microbial Drug Resistance. 1998; 4: 10712.

74. Oliveira DC, Tomasz A and de Lencastre H. The evolution of pandemic clones of methicillinresistant Staphylococcus aureus: identification of two ancestral genetic backgrounds and the associated mec elements. MicrobDrug Resist. 2001; 7: 349-61.

75. Blanc DS, Petignat C, Moreillon P, et al. Unusual spread of a penicillin-susceptible methicillinresistant Staphylococcus aureus clone in a geographic area of low incidence. Clin Infect Dis. 1999; 29: 1512-8.

76. Cookson BD and Phillips I. Epidemic methicillin-resistant Staphylococcus aureus. Journal of Antimicrobial Chemotherapy. 1988; 21(suppl C): 57-65.

77. Perez-Roth E, Lorenzo-Diaz F, Batista N, Moreno A and Mendez-Alvarez S. Tracking methicillinresistant Staphylococcus aureus clones during a 5-year period (1998 to 2002) in a Spanish hospital. J Clin Microbiol. 2004; 42: 4649-56. 
78. Amorim ML, ires de SM, Sanches IS, et al. Clonal and antibiotic resistance profiles of methicillinresistant Staphylococcus aureus (MRSA) from a Portuguese hospital over time. MicrobDrug Resist. 2002; 8: 301-9.

79. Blanc DS, Francioli P, Le Coustumier A, et al. Reemergence of gentamicin-susceptible strains of methicillin-resistant Staphylococcus aureus in France: a phylogenetic approach. Journal of Clinical Microbiology. 2001; 39: 2287-90.

80. Denis O, Deplano A, Nonhoff C, et al. National surveillance of methicillin-resistant Staphylococcus aureus in Belgian hospitals indicates rapid diversification of epidemic clones. Antimicrobial Agents and Chemotherapy. 2004; 48: 3625-9.

81. Pantazatou A, Papaparaskevas J, Stefanou I, Papanicolas J, Demertzi E and Avlamis A. Changes in the epidemiology of methicillin-resistant Staphylococcus aureus in a Greek tertiary care hospital, over an 8-year-period. IntJAntimicrobAgents. 2003; 21: 542-6.

82. Rossney AS and Keane CT. Strain variation in the MRSA population over a 10 -year period in one Dublin hospital. Eur J Clin Microbiol Infect Dis. 2002; 21: 123-6.

83. Velazquez-Meza ME, ires de SM, Echaniz-Aviles G, et al. Surveillance of methicillin-resistant Staphylococcus aureus in a pediatric hospital in Mexico City during a 7-year period (1997 to 2003): clonal evolution and impact of infection control. Journal of Clinical Microbiology. 2004; 42: 3877-80.

84. Feil EJ, Nickerson EK, Chantratita N, et al. Rapid detection of the pandemic methicillin-resistant Staphylococcus aureus clone ST 239, a dominant strain in Asian hospitals. Journal of Clinical Microbiology. 2008; 46: 1520-2.

85. Chao G, Bao G and Jiao X. Molecular epidemiological characteristics and clonal genetic diversity of Staphylococcus aureus with different origins in China. Foodborne pathogens and disease. 2014; 11: 503-10.

86. Dufour P, Gillet $\mathrm{Y}$, Bes M, et al. Community-acquired methicillin-resistant Staphylococcus aureus infections in France: emergence of a single clone that produces Panton-Valentine leukocidin. ClinInfectDis. 2002; 35: 819-24.

87. Aires de Sousa M, Sanches IS, Ferro ML, et al. Intercontinental spread of a multidrug-resistant methicillin-resistant Staphylococcus aureus clone. J Clin Microbiol. 1998; 36: 2590-6.

88. Seybold U, Kourbatova EV, Johnson JG, et al. Emergence of community-associated methicillinresistant Staphylococcus aureus USA300 genotype as a major cause of health care-associated blood stream infections. Clin Infect Dis. 2006; 42: 647-56.

89. Patel M, Waites KB, Hoesley CJ, Stamm AM, Canupp KC and Moser SA. Emergence of USA300 MRSA in a tertiary medical centre: implications for epidemiological studies. J Hosp Infect. 2008; 68: 208-13.

90. Skov RL and Jensen KS. Community-associated meticillin-resistant Staphylococcus aureus as a cause of hospital-acquired infections. Journal of Hospital Infection. 2009; 73: 364-70.

91. Marples RR and Cooke EM. Current problems with methicillin-resistant Staphylococcus aureus. Journal of Hospital Infection. 1988; 11: 381-92.

92. Witte W, Cuny C, Braulke C and Heuck D. Clonal dissemination of two MRSA strains in Germany. Epidemiollnfect. 1994; 113: 67-73.

93. Duckworth GJ and Jordens JZ. Adherence and survival properties of an epidemic methicillinresistant strains of Staphylococcus aureus compared with those of methicillin-sensitive strains. Journal of Medical Microbiology. 1990; 32: 195-200.

94. Farrington M, Brenwald N, Haines D and Walpole E. Resistance to desiccation and skin fatty acids in outbreak strains of methicillin-resistant Staphylococcus aureus. Journal of Medical Microbiology. 1992; 36: 56-60.

95. Jordens JZ, Duckworth GJ and Williams RJ. Production of "virulent factors" by "epidemic" methicillin-resistant Staphylococcus aureus in vitro. Journal of Medical Microbiology. 1989; 30: 245-52. 
96. Peacock JE, Moorman DR, Wenzel RP and MANDELL GL. Methicillin-resistant Staphylococcus aureus: microbiologic characteristics, antimicrobial susceptibilities, and assessment of virulence of an epidemic strain. Journal of Infectious Diseases. 1981; 144: 575-82.

97. Roberts JIS and Gaston MA. Protein A and coagulase expression in epidemic and non-epidemic Staphylococcus aureus. Journal of Clinical Pathology. 1987; 40: 837-40.

98. van Wamel WJB, Fluit AC, Wadström T, van Dijk H, Verhoef J and Vandenbroucke-Grauls CM. Phenotypic characterization of epidemic versus sporadic strains of methicillin-resistant Staphylococcus aureus. Journal of Clinical Microbiology. 1995; 33: 1769-74.

99. Wagenvoort JHT and Penders RJR. Long-term in-vitro survival of an epidemic MRSA phagegroup III-29 strain (letter to the Editor). Journal of Hospital Infection. 1997; 35: 322-5.

100. Amaral MM, Coelho LR, Flores RP, et al. The predominant variant of the Brazilian epidemic clonal complex of methicillin-resistant Staphylococcus aureus has an enhanced ability to produce biofilm and to adhere to and invade airway epithelial cells. Journal of Infectious Diseases. 2005; 192: 801-10.

101. Edgeworth JD, Yadegarfar G, Pathak S, et al. An outbreak in an intensive care unit of a strain of methicillin-resistant Staphylococcus aureus sequence type 239 associated with an increased rate of vascular access device-related bacteremia. Clin Infect Dis. 2007; 44: 493-501.

102. Kuhn G, Koessler T, Melles DC, et al. Comparative genomics of epidemic versus sporadic Staphylococcus aureus strains does not reveal molecular markers for epidemicity. Infection, Genetics and Evolution. 2010; 10: 89-96.

103. Vogel V, Falquet L, Calderon-Copete SP, Basset P and Blanc DS. Short term evolution of a highly transmissible methicillin-resistant Staphylococcus aureus clone (ST228) in a tertiary care hospital. PLoS One. 2012; 7: e38969.

104. Diep BA, Gill SR, Chang RF, et al. Complete genome sequence of USA300, an epidemic clone of community-acquired meticillin-resistant Staphylococcus aureus. The Lancet. 2006; 367: 731-9.

105. Uhlemann AC, Knox J, Miller $M$, et al. The environment as an unrecognized reservoir for community-associated methicillin resistant Staphylococcus aureus USA300: a case-control study. PLoS One. 2011; 6: e22407.

106. Kennedy $A D$, Otto $M$, Braughton $K R$, et al. Epidemic community-associated methicillinresistant Staphylococcus aureus: recent clonal expansion and diversification. Proc Natl Acad Sci U S A. 2008; 105: 1327-32.

107. Hung WC, Takano T, Higuchi W, et al. Comparative genomics of community-acquired ST59 methicillin-resistant Staphylococcus aureus in Taiwan: novel mobile resistance structures with IS1216V. PLoS One. 2012; 7: e46987.

108. Witte W, Kresken $M$, Braulke $C$ and Cuny $C$. Increasing incidence and widespread dissemination of methicillin-resistant Staphylococcus aureus in hospitals in central Europe, with special reference to German hospitals. Clinical Microbiology and Infection. 1997; 3: 414-22.

109. Fitzgerald JR, Meaney WJ, Hartigan PJ, Smyth CJ and Kapur V. Fine-structure molecular epidemiological analysis of Staphylococcus aureus recovered from cows. Epidemiol Infect. 1997; 119: 261-9.

110. Cuny C, Friedrich A, Kozytska S, et al. Emergence of methicillin-resistant Staphylococcus aureus (MRSA) in different animal species. International journal of medical microbiology : IJMM. 2010; 300: 109-17.

111. Strommenger B, Kehrenberg C, Kettlitz C, et al. Molecular characterization of methicillinresistant Staphylococcus aureus strains from pet animals and their relationship to human isolates. $J$ Antimicrob Chemother. 2006; 57: 461-5.

112. van Duijkeren E, Wolfhagen MJ, Box AT, Heck ME, Wannet WJ and Fluit AC. Human-to-dog transmission of methicillin-resistant Staphylococcus aureus. Emerg Infect Dis. 2004; 10: 2235-7. 
113. Lowder BV, Guinane CM, Ben Zakour NL, et al. Recent human-to-poultry host jump, adaptation, and pandemic spread of Staphylococcus aureus. Proc Natl Acad Sci U S A. 2009; 106: 19545-50.

114. Witte W, Strommenger B, Stanek C and Cuny C. Methicillin-resistant Staphylococcus aureus ST398 in humans and animals, Central Europe. Emerg Infect Dis. 2007; 13: 255-8.

115. Rabello RF, Moreira BM, Lopes RM, Teixeira LM, Riley LW and Castro AC. Multilocus sequence typing of Staphylococcus aureus isolates recovered from cows with mastitis in Brazilian dairy herds. $J$ Med Microbiol. 2007; 56: 1505-11.

116. Vanderhaeghen W, Cerpentier T, Adriaensen C, Vicca J, Hermans K and Butaye P. Methicillinresistant Staphylococcus aureus (MRSA) ST398 associated with clinical and subclinical mastitis in Belgian cows. Veterinary microbiology. 2010; 144: 166-71.

117. Loeffler A, Pfeiffer DU, Lloyd DH, Smith H, Soares-Magalhaes R and Lindsay JA. Meticillinresistant Staphylococcus aureus carriage in UK veterinary staff and owners of infected pets: new risk groups. J Hosp Infect. 2010; 74: 282-8.

118. van Cleef BA, Monnet DL, Voss A, et al. Livestock-associated methicillin-resistant Staphylococcus aureus in humans, Europe. Emerg Infect Dis. 2011; 17: 502-5.

119. Cuny C, Nathaus R, Layer F, Strommenger B, Altmann D and Witte W. Nasal colonization of humans with methicillin-resistant Staphylococcus aureus (MRSA) CC398 with and without exposure to pigs. PLoS One. 2009; 4: e6800.

120. van der Mee-Marquet N, Francois $P$, Domelier-Valentin AS, et al. Emergence of unusual bloodstream infections associated with pig-borne-like Staphylococcus aureus ST398 in France. Clin Infect Dis. 2011; 52: 152-3.

121. Fan J, Shu M, Zhang G, et al. Biogeography and virulence of Staphylococcus aureus. PLoS One. 2009; 4: e6216.

122. Price LB, Stegger M, Hasman H, et al. Staphylococcus aureus CC398: host adaptation and emergence of methicillin resistance in livestock. mBio. 2012; 3.

123. Spoor LE, McAdam PR, Weinert LA, et al. Livestock origin for a human pandemic clone of community-associated methicillin-resistant Staphylococcus aureus. mBio. 2013; 4.

124. Blanc DS. The use of molecular typing for the epidemiological surveillance and investigation of endemic nosocomial infections. Infect Genet Evol. 2004; 4: 193-7.

125. Murchan S, Kaufmann ME, Deplano A, et al. Harmonization of pulsed-field gel electrophoresis protocols for epidemiological typing of strains of methicillin-resistant Staphylococcus aureus: a single approach developed by consensus in 10 European laboratories and its application for tracing the spread of related strains. Journal of Clinical Microbiology. 2003/4; 41: 1574-85.

126. McDougal LK, Steward CD, Killgore GE, Chaitram JM, McAllister SK and Tenover FC. PulsedField Gel Electrophoresis Typing of Oxacillin-Resistant Staphylococcus aureus Isolates from the United States: Establishing a National Database. Journal of Clinical Microbiology. 2003; 41: 5113-20.

127. Mulvey MR, Chui L, Ismail J, et al. Development of a Canadian standardized protocol for subtyping methicillin-resistant Staphylococcus aureus using pulsed-field gel electrophoresis. Journal of Clinical Microbiology. 2001; 39: 3481-5.

128. Enright MC and Spratt BG. Multilocus sequence typing. Trends Microbiol. 1999; 7: 482-7.

129. Hallin M, Deplano A, Denis O, de MR, de RR and Struelens MJ. Validation of pulsed-field gel electrophoresis and spa typing for long-term, nationwide epidemiological surveillance studies of Staphylococcus aureus infections. Journal of Clinical Microbiology. 2007; 45: 127-33.

130. Koreen L, Ramaswamy SV, Graviss EA, Naidich S, Musser JM and Kreiswirth BN. Spa typing method for discriminating among Staphylococcus aureus isolates: implications for use of a single marker to detect genetic micro- and macrovariation. Journal of Clinical Microbiology. 2004; 42: 792-9. 131. Shopsin B, Gomez M, Montgomery SO, et al. Evaluation of protein A gene polymorphic region DNA sequencing for typing of Staphylococcus aureus strains. Journal of Clinical Microbiology. 1999; 37: 3556-63. 
132. Basset P, Hammer NB, Kuhn G, Vogel V, Sakwinska O and Blanc DS. Staphylococcus aureus clfB and spa alleles of the repeat regions are segregated into major phylogenetic lineages. Infect Genet Evol. 2009; 9: 941-7.

133. Kuhn G, Francioli P and Blanc DS. Double-locus sequence typing using $c / f B$ and $s p a$, a fast and simple method for epidemiological typing of methicillin-resistant Staphylococcus aureus. J Clin Microbiol. 2007; 45: 54-62.

134. Tang YW, Waddington MG, Smith DH, et al. Comparison of protein A gene sequencing with pulsed-field gel electrophoresis and epidemiologic data for molecular typing of methicillin-resistant Staphylococcus aureus. Journal of Clinical Microbiology. 2000; 38: 1347-51. 


\section{Box 1. Common typing methods for $S$. aureus}

The epidemiology of $S$. aureus has been analyzed by an array of genotypic and phenotypic typing methods. Here, we review the methods that are currently the most widely used:

Pulsed-field gel electrophoresis - Pulsed-field gel electrophoresis (PFGE) is considered as the gold standard for $S$. aureus typing because it shows the highest discriminatory power. This method is based on the restriction of whole DNA with an enzyme that cuts only rarely. The enzyme SmaI is generally used for $S$. aureus. Digestion with this enzyme gives between 20 and 50 large fragments (between 10 and $700 \mathrm{~kb}$ ) that can only be separated using a pulsed gel electrophoresis. Although this method is reproducible within a laboratory, the data can be ambiguous ${ }^{121}$ and inter-laboratory studies have highlighted the problem of standardization ${ }^{122}$. PFGE standardization can only be obtained with a strict control of all parameters. For example, standardized protocols have been developed for PFGE typing by the American and Canadian CDCs to build nationwide databases ${ }^{123,124}$.

Multi-locus sequence typing - Multi-locus sequence typing (MLST) is a typing method that combines the sequence of several housekeeping genes, and is essentially a sequenced-based version of multi locus enzyme electrophoresis (MLEE) ${ }^{125}$. MLST has been designed to analyze and compare genetic variation in worldwide collections of bacterial pathogens. It gives important information about the nucleotide divergence of the core genome, the clonal origin of one group of strains, the recombination rate and the phylogenetic relationship among strains. The main advantage of this method is that it gives unambiguous data that are reproducible among laboratories. Its limitations are its cost and its relatively low discriminatory power that prevent its use for local epidemiology. For $S$. aureus, the amplification and the sequencing of $450-500 \mathrm{bp}$ of the seven genes arcC, aroE, glpF, gmk, pta, tpi and yqiL have been retained ${ }^{57}$. Alleles at each locus are assigned according to differences in nucleotide sequences. The allelic profile of the seven loci defines the sequence type (ST). For example, isolates with the profile 2-3-1-1-4-4-3 belong to ST 239, of which the Brazilian clone is an example. An international database containing more than 3,000 isolates and 1,600 STs is available at http://www.mlst.net.

spa-typing - spa-typing is based on polymorphism of the spa locus of $S$. aureus, which codes for the protein A. This locus is highly polymorphic due to an internal variable region of short tandem repeats. It varies not only in numbers but also because of nucleotide substitutions within individual repeats. A spa profile is identified by a succession of number representing each individual repetition of the $\mathrm{X}$ region. An international database has been created to standardize the nomenclature of the spa types (http://spaserver.ridom.de). Several studies have shown the value of this method for $S$. aureus typing ${ }^{126-128}$. However, this method might reflect homoplasy ${ }^{31}$, its discriminatory power is below PFGE ${ }^{129-131}$ and the analysis of spa data is not simple.

Double Locus Sequence typing - We developed a new typing method called Double Locus Sequence Typing (DLST) based on the analysis of partial sequences (ca. $500 \mathrm{bp}$ ) of the highly variable $c l f B$ and $s p a$ genes ${ }^{130}$. This method was shown to be far more discriminatory than $s p a-$ typing and matched the high resolution of PFGE. In addition, the combination of high typeability and reproducibility with low cost, ease of use and unambiguous definition of types makes this method promising for epidemiological analyses. It is important to note that although $s p a$-typing and DLST investigate polymorphisms in the spa gene, these methods do not analyse the same regions of the gene. Therefore the spa alleles determined by these two methods are not identical. 
Whole-genome sequencing (WGS) - Recently, high-throughput or whole-genome sequencing technologies have provided a significantly improved discriminatory power to study the complete genomes of various bacterial pathogens. WGS techniques generate from bacterial samples multiple short reads that can be assembled based on overlapping regions (de novo assembly), and/or mapped to a previously published reference genomes, which then enable the comparison between bacterial strains that genetically diverge at a single nucleotide. Such precise identification and classification of bacterial strains, as well as the parallel sequencing of different bacterial strains in single runs at low costs with a quicker turn-around times have made WGS the most convenient tool for clinical diagnostic investigations in real-time and for tracking disease outbreaks. 